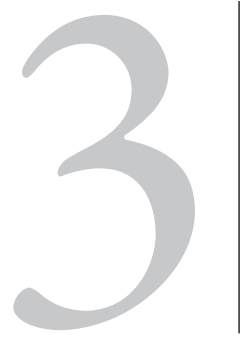

\title{
EL DEBATE SOBRE LA ELECCIÓN DIRECTA DEL ALCALDE. RETOS Y OPORTUNIDADES EN ESPAÑA
}

THE DISCUSSION ON MAYOR'S

DIRECT ELECTION. CHALLENGES

AND OPPORTUNITIES IN SPAIN

Mayte Salvador Crespo ${ }^{1}$

Recibido: 03/04/2016

Aceptado: 06/05/2016

\section{RE S UM E N}

Las medidas de regeneración democrática activadas en España para paliar los efectos de la crisis económica y política han puesto otra vez de actualidad el debate sobre la posibilidad de reformar el sistema electoral local para elegir directamente al Alcalde. A partir del análisis de la ley electoral española y tomando como referencia algunas experiencias europeas, este artículo trata de examinar la conveniencia de un cambio como ése. Por un lado se defiende que se reforzaría la rendición de cuentas del Alcalde ante los ciudadanos y, por tanto, aumentaría la legitimidad democrática del municipio. Sin embargo, puede ser también causa de disfunciones en la actividad ordinaria del Ayuntamiento si no se abordan paralelamente otras reformas en la legislación española sobre régimen local.

\section{PA L A B R A C L A VE}

Alcalde, Pleno, gobierno local, legitimidad democrática, sistema electoral. 


\section{A B S T R A C T}

The measures of democratic renewal activated in Spain to alleviate the impact of the economic and political crisis have once again spotlighted attention to the debate about the convenience of changing the local electoral system to introduce the direct election of the Mayor. Based on the analysis of the Spanish electoral law, and taking some European experiences as comparative reference points, the article examines the appropriateness of such a move. On the one hand, it is argued that this particular reform would strengthen the accountability of the Mayor to the local electorate, thus enhancing the political legitimacy of the municipality. However, it may also cause dysfunctions in the ordinary activity of the Town council if other reforms in Spanish local government legislation are not addressed at the same time.

\section{K E Y W O R D S}

Mayor, Plenary, local government, democratic legitimacy, electoral system.

\section{CUESTIONES PREVIAS}

España es el único país del mundo en que nunca ha dejado de crecer el número de municipios, según los últimos datos de los que se disponen a 8.128 municipios. Conforme a la Ley Orgánica 5/1985, de 19 de junio, del Régimen Electoral General, (en adelante LOREG), cada término municipal constituye una circunscripción. Esta Ley establece que el cuarto domingo de mayo cada cuatro años se celebrarán las elecciones municipales ${ }^{2}$. Pues bien, durante los últimos quince años y de forma más apremiante en las fechas próximas a la celebración de elecciones municipales, se avivan los debates y propuestas orientadas a introducir modificaciones en el sistema electoral, y de manera particular sobre el mejor sistema para la elección de los alcaldes introduciendo la posibilidad y conveniencia de un sistema de elección directa. Esta posibilidad no es ajena a la legislación electoral española sobre régimen local, pero actualmente se aplica solamente a los supuestos del Concejo Abierto.

2. En España se han celebrado las últimas elecciones municipales el 24 de mayo de 2015 y ese mismo dia y también porque asi lo dispone la misma Ley, elecciones autonómicas en aquellas comunidades autónomas en que estuvieran previstas elecciones antes del 24 de septiembre de 2015. Es decir: en Asturias, Cantabria, Navarra, Castilla y León, La Rioja, Comunidad Valenciana, Comunidad de Madrid, Castilla-La Mancha, Región de Murcia, Canarias, Islas Baleares, Aragón y Extremadura, y en las dos ciudades autónomas (Ceuta y Melilla). También hubo elecciones a las Juntas Generales del País Vasco; a los Cabildos Insulares canarios; a los Consejos Insulares de Baleares; al Consejo General de Arán; a los concejos de Navarra; y a las entidades de ámbito territorial inferior al municipio. 
Esto se explica porque la elección directa del alcalde se identifica también y, no siempre con razón, con un incremento de la calidad democrática del gobierno local. Sin embargo, paradójicamente, y aun cuando la propuesta de elección directa del alcalde se ha planteado tanto por partidos de izquierdas como de derechas, en la práctica, ninguno de ellos ha conseguido hasta el momento llegar a un acuerdo para impulsar una reforma legal en este sentido. El Primer Borrador del Libro Blanco para la reforma del Gobierno local, publicado en enero de 2005, se expresaba de forma más dubitativa sobre esta posibilidad, que desaparecerá ya por completo del texto definitivo -publicado unos meses después-, y no volverá a ser planteada por el Gobierno del partido socialista hasta fechas recientes ${ }^{3}$. El PP, por su parte ha venido defendiendo la elección como alcalde del candidato de la lista más votada, una de las posibles modalidades de la elección directa, si bien este partido no ha concretado de forma detallada los términos en que se articularía su propuesta ${ }^{4}$.

Estas proposiciones se insertan por tanto en un debate que se ha intensificado en los últimos años en torno al sistema de gobierno municipal y que ha cobrado una especial relevancia por varios motivos. De una parte, por las reivindicaciones realizadas por las mismas corporaciones locales, especialmente a través de sus entes asociativos (Federación Española de Municipios y Provincias -FEMP- y sus federaciones autonómicas). De otra, por las polémicas planteadas tras la celebración de las elecciones locales cuando en muchas ciudades el alcalde no ha resultado siendo el cabeza de lista del partido más votado al pactar varias fuerzas políticas y apoyar a un candidato alternativo.

El objeto de este trabajo es analizar a la vista del Derecho comparado europeo y del debate doctrinal desarrollado en España durante los últimos años, las

3.Cfr. MINISTERIO DE ADMINISTRACIONES PUBLICAS, Primer Borrador del Libro Blanco para la Reforma del Gobierno Local en España, 2005, págs. 102-104; Libro Blanco para la Reforma del Gobierno Local, 2005, pág. 94: "En general, puede sostenerse que el vigente sistema electoral español garantiza un grado suficiente de representación del pluralismo político y la gobernabilidad de las instituciones locales".

http://www.seap.minhap.gob.es/dms/es/web/publicaciones/centro_de_publicaciones_de_la_sgt/Monografias/ parrafo/0111111111111111118/text_es_files/Libro-Blanco-Gobierno-Local.pdf (consultado en abril de 2016).

4. La última propuesta del actual partido en el Gobierno de la Nación (el Partido Popular), durante el verano de 2014, casi un año antes de la celebración de las últimas elecciones municipales en España, pretendía asegurar que gobernara el alcalde de la lista más votada en los municipios. De este modo se buscaba una "regeneración democrática" en el ámbito municipal. Esta iniciativa se confundió con una supuesta "elección directa del alcalde" y fue objeto de debates en los medios de comunicación durante algunos días para, finalmente, caer de nuevo en el olvido. "El PP defenderá la elección directa de alcaldes en todos los ayuntamientos", El País, 23.07.2014. Disponible on-line: http://politica.elpais.com/politica/2014/07/23/actualidad/1406141152_626901.html (consultado el 17.09/2015). 
consecuencias que podría tener la modificación del sistema actual de elección de los alcaldes. Plantear si la opción por un sistema de elección directa o de efectos equivalentes (prima de mayoría a la lista más votada), en la línea de los cambios operados en algunos países europeos que ya han apostado por un sistema de elección directa de sus dirigentes municipales ${ }^{5}$, contribuiría en el caso español a mejorar el sistema de gobierno municipal en orden a una mayor representatividad y mejor gobernabilidad de los municipios.

\section{L A E L E C C I ÓN D E L A L C A L D E E N L A VIGENTE CONSTITUCIÓN ESPAÑOLA D E 1978}

La Constitución española en su art. 140 establece dos sistemas posibles para la elección del alcalde: la directa que cuenta con algún precedente históri$\mathrm{co}^{6}$, y la indirecta o por los concejales que es la que ha gozado de una mayor tradición en la legislación. Es decir que la Constitución actual admite tanto el sistema directo como el indirecto de modo que ha sido la legislación sobre el Régimen electoral general (la mencionada LOREG de 1985) y no la norma fundamental la que ha optado por concretar los diferentes modelos. La Constitución no petrifica la forma de gobierno local, sino que abre un abanico de posibilidades a las dos referidas e incluso contempla una tercera, basada en la combinación de las dos anteriores, según el tamaño u otras características del municipio.

En los sistemas de Concejo abierto concebidos para los municipios de menos de 100 habitantes y aquellos que tradicionalmente cuenten con este régimen singular de gobierno y administración, la elección del alcalde se produce a través de un sistema directo y mayoritario conforme a lo dispuesto en el art. 29.1 de la Ley Reguladora de las Bases del Régimen Local 7/1985, de 2 de abril (en adelante LBRL) y en el art. 179.2 de la LOREG.

El tercer sistema de elección del alcalde es el previsto para los municipios con población comprendida entre 100 y 250 habitantes (art. 184 y 196.5 de la LOREG). "Pueden ser candidatos a alcalde todos los concejales; si alguno de los candidatos obtiene la mayoría absoluta de los votos de los concejales

5. Se analizarán los casos de Alemania, Inglaterra, Irlanda, Italia, Portugal y Francia.

6. Asi se contemplaba en el Real Decreto de 30 de diciembre de 1843, en la Ley de ayuntamientos de 5 de julio de 1856 y en la Ley municipal puesta en vigor por Decreto de 21 de octubre de 1868. La elección del alcalde por el pleno del ayuntamiento se contempló en la Ley de 20 de agosto de 1870, asi como en el Estatuto municipal de 1924. 
es proclamado electo; si ninguno obtuviese dicha mayoría será proclamado alcalde el concejal que hubiere obtenido más votos populares en las elecciones de concejales". Se trata de un sistema de elección indirecta del alcalde que, sin embargo, incrementa la participación de los electores, dado que plantea sobre la base de unas listas desbloqueadas. Así los electores pueden expresar sus preferencias al no votar a la totalidad de la lista, sino un número de concejales de los allí propuestos (hasta un máximo de cuatro). En el caso de que ningún candidato obtenga la mayoría absoluta resultaría elegido el que haya obtenido mayor número de votos populares.

Por último, el sistema más común y también el más aplicado en España, es el contemplado para la elección del alcalde en los municipios de más de 250 habitantes que se aplica con carácter general tanto al régimen de municipios de gran población. Estos saltos de escala y la heterogeneidad en cuanto al tamaño de los municipios han llevado a cuestionar si resulta acertada la aplicación de un sistema de selección uniforme a municipios tan heterogéneos, o si habría que introducir, o tener en cuenta, ciertas diferencias en función de la población del municipio.

La elección del alcalde en estos casos se basa en un sistema de elección indirecta y proporcional muy similar al aplicado para la selección de los Diputados en el Parlamento nacional, aunque con la salvedad de que no se tienen en cuenta las candidaturas que no obtengan al menos el 5 por 100 de los votos válidamente emitidos en la circunscripción. Los alcaldes seleccionados a partir de este sistema cuentan con una legitimidad indirecta ya que no son elegidos directamente por los electores sino a partir del voto de los concejales. Solamente en el caso de que no consiguieran la mayoría absoluta, requerida en este sistema, sería elegido alcalde el candidato que encabece la lista más votada. El carácter subsidiario de esta segunda posibilidad, y los pactos postelectorales entre las distintas fuerzas políticas, hacen que esta segunda opción sea raramente utilizada y que en consecuencia, la persona que ostente la alcaldía no sea precisamente la que más apoyos consiguió de los electores sino la que haya conseguido el mejor pacto post-electoral.

Así, en la mayor parte de los municipios españoles, es decir, los que tienen más de 250 habitantes, el sistema de elección de los alcaldes se basa en un sistema indirecto aunque sociológicamente para los ciudadanos pueda ser interpretado como un sistema de elección directo. Esto es así, porque para seleccionar a su candidato o partido a la alcaldía de su municipio, los electores se fijan en la persona que encabeza la lista electoral más afín a sus preferencias políticas, produciéndose una identificación inmediata entre 
cabeza de lista y candidato a la alcaldía con independencia de que la selección final del alcalde transcurra por un procedimiento legal de selección indirecta a partir de los votos de los concejales que no es apreciado en la práctica por los votantes.

\section{EL SISTEMA ELECTORALACTUAL Y SUS EFECTOS EN EL ÁMBITOLOCAL}

El sistema electoral vigente en España para las elecciones municipales presenta una diferencia fundamental con el de las elecciones al Congreso de los Diputados: la existencia de una única circunscripción para la elección de cada cuerpo representativo (art. 179.1 LOREG). En otras palabras, la circunscripción coincide con el municipio. Por tanto, no se plantean los problemas de pérdida de restos o de distorsión en la representación territorial asociados a la pluralidad de circunscripciones. Hay que añadir, además, que la magnitud de la mayor parte de las circunscripciones es elevada, pues los municipios de más de 2.000 habitantes -en los que reside el 93,67\% de la población española ${ }^{7}$ - eligen un mínimo de 11 representantes (concejales). Con estas condiciones, parece evidente que la aplicación de la misma fórmula electoral que se usa en las elecciones al Congreso (regla d'Hondt) habrá de generar una mayor proporcionalidad. No obstante, ésta se reduce a su vez por la existencia de una barrera electoral del 5\% de los votos válidos emitidos (art. 180 LOREG). Pero aun así, el actual sistema electoral municipal español merece una valoración positiva, en cuanto permite traducir en cada municipio con bastante fidelidad, la distribución de preferencias del respectivo cuerpo electoral. Los problemas que plantea se relacionan más bien con la otra gran función de los sistemas electorales, concretamente la capacidad de generar gobiernos estables. La proporcionalidad del sistema hace más difícil que la lista ganadora alcance la mayoría absoluta de los puestos.

Un efecto relevante del sistema electoral municipal es, pues, la relativa dificultad de formar mayorías absolutas, especialmente en los municipios más importantes, pues para alcanzarla se requiere un porcentaje de votos muy próximo a la mitad de los sufragios. Por sí mismo, este efecto no merecería

7. De los 8.111 municipios existentes en España, sólo el 28,25\% (2291) tienen más de 2.000 habitantes, pero en ellos reside el 93,67\% de la población (42.341.464 habitantes); mientras que en los 5820 municipios con menos de 2000 habitantes (el 71,75\%) residen únicamente un total de 2.859 .273 personas, es decir, el 6,33\% de la población. Fuente: Instituto Nacional de Estadistica. Este sistema electoral no se aplica en los 932 municipios que, de acuerdo con lo previsto en el art. 29 LBRL, funcionan en régimen de concejo abierto, donde únicamente se elige al Alcalde por sistema mayoritario uninominal a una vuelta, ni en los restantes 1.651 municipios de menos de 250 habitantes, que siguen la fórmula mayoritaria de voto limitado 
una valoración negativa, pues también en las elecciones generales el partido ganador ha carecido de mayoría absoluta en la mayor parte de las Legislaturas, sin que ello haya generado inestabilidad alguna; la ausencia de mayoría absoluta obliga además al partido ganador a un estilo de gobierno caracterizado por la disposición al diálogo y al acuerdo, lo que sin duda debe calificarse como positivo. Sin embargo, en el ámbito municipal este factor ha provocado, con relativa frecuencia desde las primeras elecciones municipales democráticas, que no haya gobernado el partido con mayor apoyo popular. Este hecho puede crear en el electorado una sensación de cierta pérdida de legitimidad de los gobiernos locales, dificultando que las elecciones cumplan una de sus funciones más importantes: legitimar a los titulares del poder político. En efecto, los ciudadanos pueden tener la sensación de que se ignora su voluntad y de que su voto no sirve para nada; y, de hecho, una de las críticas más reiteradas en la opinión pública al sistema electoral municipal se refiere precisamente a la posibilidad de que se erija con la Alcaldía un partido que no ha sido el ganador de las elecciones.

En realidad, la posibilidad de que detente el gobierno municipal un partido distinto del partido más votado no es consecuencia tanto de la fórmula de asignación de escaños, sino de otra característica esencial del sistema electoral municipal: la elección indirecta del alcalde. En efecto, de acuerdo con lo dispuesto por el art. 196 LOREG, el alcalde es elegido por los concejales entre aquellos que hayan encabezado las listas electorales; sólo en caso de que ninguno obtenga mayoría absoluta, se aplica un procedimiento subsidiario, consistente en proclamar alcalde a quien haya encabezado la lista que haya obtenido mayor número de votos en las elecciones. Coherentemente con este sistema, si es la Corporación municipal quien elige al alcalde, resulta también lógico que pueda también revocar esa elección, razón por la cual se ha regulado un mecanismo de moción de censura en el ámbito local.

A este respecto es importante señalar quede entre las mociones de censura que se presentan en los municipios, una parte de ellas se encuentran asociadas a casos de transfuguismo entendido como el abandono por un representante electo de la formación política con que concurrió a las elecciones, alterando en consecuencia la correlación de fuerzas resultante de las mismas. En él ámbito local este fenómeno ha suscitado una especial preocupación, debido a la relativa frecuencia con que se ha producido, normalmente con la finalidad de sustituir un Gobierno municipal de un partido por otro con siglas diferentes, y en muchas ocasiones bajo la influencia de intereses fraudulentos, generando un sentimiento de descrédito de los gobiernos locales entre la ciudadanía. Y, aun cuando no cabe descartar que en 
algún caso esta conducta pueda ser la respuesta al cambio de orientación o a la ruptura de los compromisos electorales por parte de una formación política, en la generalidad de las ocasiones son el concejal tránsfuga y quienes se benefician de su conducta los que traicionan la voluntad del electorado ${ }^{8}$.

Es precisamente la existencia de una relación de confianza entre el alcalde y el pleno de la Corporación, a imagen del existente en el ámbito estatal, la que permite que se produzcan situaciones como las descritas (gobierno por un partido distinto del más votado, mociones de censura, transfuguismo) ${ }^{9}$.

El modelo tradicional de organización de los municipios responde al denominado de asamblea o corporativo, es decir, el alcalde es competente para la dirección política del gobierno y la administración municipal (art. 21 LBRL), mientras que el pleno es el órgano encargado de las potestades normativas y funciones de planificación (art. 22 LBRL). La junta de gobierno local es el órgano de apoyo y asistencia al alcalde en las funciones delegadas. Es el pleno de la Corporación municipal el que, como si de un Parlamento se tratara, elige al alcalde (salvo en el procedimiento subsidiario del art. 196.c LOREG), es decir, al presidente del Gobierno municipal, que -tal y como disponen los arts. 23 y 126 LBRL- nombra y separa libremente a los miembros de su Gobierno (los cuales pueden incluso, en el régimen de los municipios de gran población establecido por la Ley de Modernización del Gobierno Local de 2003, no tener la condición de concejales: art. 126.2 LBRL); y el pleno tiene la posibilidad de revocar o confirmar posteriormen-

8. Como respuesta a esta preocupación, el Ministro de Administraciones Públicas y la práctica totalidad de los partidos políticos con representación parlamentaria en las Cortes Generales suscribieron en 1998 un "Acuerdo sobre un Código de Conducta Política en relación con el transfuguismo en las Corporaciones Locales", conocido habitualmente como Pacto Antitransfuguismo, que posteriormente ha sido renovado en dos ocasiones (2000 y 2006). Recientemente en 2015 tras la celebración de elecciones municipales desde el gobierno se ha propuesto una nueva renovación del pacto para incluir en el mismo a las nuevas fuerzas politicas que han obtenido representación en los ayuntamientos españoles (Podemos y Ciudadanos). Este acuerdo político, y la reforma del art. 73.3 LBRL llevada a cabo en 2003 en cumplimiento del mismo -por la Ley 57/2003, de 16 de diciembre, de medidas de modernización del Gobierno local (en adelante, LMGL)-, que crea la figura del concejal no adscrito y prohíbe que los concejales que abandonan su formación politica de origen pasen a otro Grupo municipal o constituyan uno nuevo, aunque no han conseguido detener la práctica del transfuguismo, si lo han reducido notablemente. Desde su creación la comisión de seguimiento ha conocido 635 de mociones de censura de las cuales 210 han sido calificadas de transfuguismo, pero su frecuencia se ha venido reduciendo con el paso de los años de manera "espectacular": entre 1999 y 2003 hubo 59 casos, que subieron a 80 en los cuatro siguientes, pero entre 2007 y 2011 la cifra bajó a 71 y en los últimos cuatro años sólo ha habido media docena de denuncias (tres en 2012, dos en 2013 y sólo una en 2014). Sobre esta cuestión puede consultarse De la Torre Martínez, Lourdes (2014: 31-34) y Salazar Benitez (2007: 357-412).

9.Esta naturaleza "parlamentaria" del sistema de gobierno local español, más intensa todavía en el régimen de los municipios de gran población establecido por la LMGL, ha sido observada por la generalidad de la doctrina: cfr. vg. Márquez Cruz (2007: 46-61); Salazar Benitez (2006: 153-154); Salvador Crespo (2008: 81-10); Gavara de Cara (2015: 161-186). 
te esa confianza otorgada al alcalde, a través de dos instituciones clásicas del parlamentarismo que la LOREG exporta a las Entidades locales: la moción de censura constructiva (art. 197) y la cuestión de confianza (art. 197 bis). Se ha olvidado, sin embargo, otro elemento tradicionalmente integrante del parlamentarismo, como es la facultad de disolución anticipada de la asamblea por el titular del ejecutivo con la que no cuentan los alcaldes en el ámbito municipal como ya se ha indicado.

Esta última omisión permite advertir las limitaciones de la "parlamentarización" del sistema de gobierno municipal, pues, en el sistema parlamentario, la facultad del Parlamento de censurar al Presidente tiene como razonable contrapeso la del Presidente de disolver el Parlamento: es decir, la relación de confianza que une a Parlamento y Gobierno ha de ser mutua; y no unidireccional como sucede en los gobiernos municipales, en los que el alcalde no tiene la facultad de disolver la Corporación, entre otras razones porque propiamente no existe diferencia entre alcalde y dicha Corporación. $\mathrm{Y}$ este es el verdadero problema porque se han importado instituciones diseñadas para vertebrar la relación entre dos poderes diferentes del Estado -el poder legislativo (que es el que eligen los ciudadanos) y el poder ejecutivo-, aplicándolas a la regulación de las relaciones internas entre lo que no son más que dos órganos de una y la misma Administración en el ámbito municipal. Conviene recordar que a través de las elecciones locales no se conforman dos instituciones diferentes -Parlamento y Gobierno- ni por tanto dos poderes diferentes -Ejecutivo y Legislativo-, sino una única institución, de naturaleza administrativa, carente de potestad legislativa -que es la razón de ser del Parlamento-, y en cuyo seno sólo existe una distribución de funciones, y no una auténtica división de poderes, pues el único poder que ejerce la Corporación Local es el ejecutivo. Así las cosas, puede afirmarse que la relación de confianza entre el alcalde y el pleno del ayuntamiento no opera en la práctica en el sistema actual.

Hay que añadir, además, que es el alcalde el cabeza visible y quien ostenta la titularidad del ejecutivo local, como se refleja en su amplio elenco competencial, reforzado en los arts. 21 y 121 LBRL, y que son estos factores los que han llevado a calificar al sistema de gobierno local español como "semipresidencialista" (Marquez, 2007: 46-61 y Pendás, 1993: 573-574) ${ }^{10}$. Esta es

10. Márquez califica el sistema de gobierno local español como "semipresidencialista" desde el punto de vista del rol del alcalde y como "parlamentario" en relación con las funciones y organización del Pleno: es fácil advertir que, en realidad, ante lo que nos encontramos es ante un sistema incoherente, entre otras razones porque lo propio de un sistema "semipresidencialista" es que el Presidente sea elegido directamente por los ciudadanos. Este carácter hibrido del sistema de gobierno local en España ha sido también expuesto por Pendás (1993: 573-574). 
otra diferencia con el sistema parlamentario, en el que el titular de la potestad legislativa es el Parlamento. Por ello, si se quiere replantear un cambio en el sistema electoral local en lo que a la elección del alcalde se refiere sería necesario partir de las principales debilidades que se detectan en el sistema vigente para tratar de explorar si la apuesta por un nuevo sistema de elección directa podría satisfacerlas.

Las debilidades normalmente apuntadas del sistema de elección actual son la legitimidad indirecta del alcalde que se vería reforzada optando por un sistema de elección directa con el cual tanto el pleno como el alcalde, órganos visibles del poder municipal, serían elegidos directamente por los ciudadanos. Y, en segundo término, el problema de la gobernabilidad del municipio. En este sentido, un sistema de elección directa del alcalde podría contribuir a garantizar la formación de mayorías y por tanto poner freno a los fenómenos de transfuguismo que plantean en la actualidad serias dificultades de gobernabilidad de los ayuntamientos. En este caso la reforma debería de acompañarse adicionalmente de un mecanismo que dotase al alcalde del necesario respaldo electoral como podría ser el sistema de prima de mayoría italiano. Sin embargo resulta necesario recalcar que la mejor gobernabilidad del municipio está reñida con la mayor representatividad. Cuando aumenta una disminuye la otra, puesto que como se ha señalado, "para ganar en representación hay que aumentar la proporcionalidad del sistema electoral. Pero esa misma proporcionalidad puede conducir a una mayor fragmentación de la representación", dificultando en consecuencia la gobernabilidad del ayuntamiento (García Fernández, 2001: 235) y (Mahíllo y Galán, 2015: 187-209).

De modo que el decidir por aumentar la gobernabilidad o la representatividad es un dilema al que tiene que enfrentarse cualquier reforma que se emprenda en este sentido. La tercera ventaja aludida sería un posible aumento de la participación electoral si se optara por un sistema de elección directa del alcalde. En todo caso, hay que tener muy presente que la apuesta por una elección directa del alcalde llevaría aparejada una modificación en profundidad del régimen de atribuciones competenciales de todos los órganos locales (Alcalde, Junta de Gobierno y Pleno) para dotar tal elección de la legitimidad necesaria lo que implicaría necesariamente un cambio no solo en la legislación electoral sino también en toda la legislación sobre régimen local ${ }^{11}$ 
Para plantearnos la hipótesis de una reforma del Régimen electoral local en España orientada a un cambio en el modo de elección del alcalde, hemos partido de un vínculo causa efecto entre los objetivos que con tal reforma se quieren conseguir y las medidas que para implementar tal fin habría que poner en marcha. Normalmente en cada uno de los países europeos en los que se ha introducido el sistema de elección directa de los alcaldes han perseguido uno o varios de los siguientes objetivos: 1) Reforzar la posición del gobierno local en el sistema político; 2) robustecer la democracia local promoviendo una mayor implicación de los ciudadanos; 3) fortalecer el liderazgo en la estructura del ayuntamiento para una dirección y gestión más eficaz, o 4) minimizar el impacto de la política de partidos en el gobierno local, creando fuentes alternativas de liderazgo político(Navarro y Sweeting, 2015: 108).

Y en general todos ellos pueden reconducirse al interés por reforzar la legitimidad del sistema mediante el sistema de selección del alcalde y su capacidad para representar a su electorado, así como en la de desarrollar con mayor eficacia las funciones de gobierno en el ámbito municipal. En realidad, el modelo de la elección directa forma parte de una tendencia general de los gobiernos locales hacia el reforzamiento de los ejecutivos, lo que a su vez se corresponde con una pérdida del peso del pleno municipal en la gobernanza local (Denter y Laurence, 2005: 8). Pero hay que recordar que esta tendencia no siempre obedece a reformas electorales concretas sino que pude venir propiciada por otros factores como por ejemplo una reorganización de las competencias del alcalde, tal y como ha ocurrido en España.

En España las reformas operadas en la LBRL han ido precisamente en este sentido. Las dos modificaciones más importantes sufrida por la Ley de Bases de Régimen Local, antes de la reciente Ley 27/2013, de 27 de diciembre de Racionalización y Sostenibilidad de la Administración Local, fueron la del año 1999, realizada tras el denominado Pacto local, y la de 2003, de

11. Así lo indicó el Consejo de Estado, en su Informe sobre las propuestas de modificación del Régimen Electoral General, de 24 de febrero de 2009 . En el apartado relativo a la elección del alcalde señala: "la forma de elección del alcalde, puede decirse que afecta por entero a un sistema de gobierno. En efecto, la regulación de esta materia no solo incide en el sistema electoral de las corporaciones locales (aspecto bajo el cual queda reservada a la Ley orgánica electoral), sino en la forma del gobierno municipal en su conjunto (regulada ésta en sus líneas principales, en la legislación estatal y autonómica sobre régimen local)".

http://www.consejo-estado.es/pdf/REGIMEN-ELECTORAL.pdf (consultada el 21 de abril de 2016). 
Modernización del gobierno local. En la primera de ellas se reforzaron las competencias del alcalde en detrimento de las competencias del pleno, se redujeron los asuntos de mayoría absoluta y se suprimieron las mayorías de dos tercios. Como compensación se modificó la regulación las comisiones informativas, se dotó a la oposición de la posibilidad de convocar un pleno extraordinario de modo semiautomático y se distinguió claramente en las sesiones plenarias la parte destinada a la adopción de acuerdos de la parte destinada al control político del gobierno. En la reforma de 2003 se trasladó, en los municipios de gran población, el peso del gobierno municipal a la junta de gobierno local, nuevamente en detrimento del pleno. El reforzamiento del papel del alcalde y el menoscabo de las atribuciones del pleno ha sido justificado, no solo por la necesidad de asegurar gobiernos con capacidad resolutiva, ágiles en la toma de decisiones y capaces de evitar eventuales bloqueos políticos por el máximo órgano de representación municipal, también, como acertadamente señala el profesor Zafra, para evitar un efecto perverso de la democracia que supondría reconocer funciones de gobierno a las minorías situadas en la oposición. Ciertamente las minorías, aunque no puedan gobernar por sí, sí pueden impedir el gobierno o dificultarlo en numerosos casos (Zafra, 2009: 593-600).

La legislación de régimen local y la legislación electoral han previsto sistemas para impedir el bloqueo por el pleno de la acción del alcalde: así cabe la posibilidad de ligar la aprobación de determinados acuerdos de especial importancia a una cuestión de confianza (novedad recogida en la ley de régimen electoral tras el Pacto local) o la posibilidad, introducida por la reforma de 2013, de que el presupuesto sea aprobado, en determinados supuestos excepcionales, por la junta de gobierno local en sustitución del pleno. Como último recurso, cabe que el pleno sustituya a un alcalde por otro mediante una moción de censura.

Sí lo que se pretende es mejorar la estabilidad de los gobiernos locales, habría que hacerlo a través de un sistema que favorezca unas mayorías sólidas, introduciendo mecanismos que ayuden a reforzar la figura del alcalde y consecuentemente sus funciones ejecutivas. Otro camino sería mediante la implementación de vías que favorezcan la legitimación directa de los alcaldes, lo que exigiría a su vez el diseño de mecanismos necesarios para el control de su gestión.

En este sentido la elección directa del alcalde se ofrece como la panacea capaz de dotar de una mejor gobernabilidad y estabilidad a las entidades locales. Sin embargo, estos dos objetivos no se alcanzan con la sola apuesta por un sistema de elección directa (en la práctica actualmente existente si 
no se consigue la mayoría absoluta del número de concejales), puesto que también es resultado de otros elementos asociados con el sistema electoral y con el régimen de organización interna de cada municipio. Por estos motivos la elección directa del alcalde tiene que ir necesariamente vinculada a una reforma general de las instituciones municipales diferenciando de la forma más clara posible entre las instituciones encargadas de las funciones de gestión y gobierno (alcalde y junta de gobierno) y la institución encargada del control (pleno). Si se opta por un cambio de legitimidad democrática del alcalde mediante un sistema de elección directa entonces también habría que separar de manera más clara las funciones de control e impulso político de las funciones de ejecución y gestión (García Fernández, 2001: 212).

El alcalde en un sistema de corte presidencialista como este que se propone a partir de su elección directa gozaría de la capacidad discrecional de elegir y destituir a los miembros de la junta de gobierno, así como de nombrar para formar parte de este órgano colegiado a otros miembros que no gocen de la condición de concejal en su condición de expertos que gocen de la confianza del alcalde, y en virtud de la misma, colaboren en las tareas del gobierno.

La elección directa del alcalde también conllevaría un cambio en el sistema de relación entre el alcalde y el pleno del ayuntamiento y particularmente por lo que respecta a los mecanismos de control tales como la moción de censura y la cuestión de confianza (García Morales, 2011:205-258). En este caso el elemento determinante para la elección del alcalde no será tanto la confianza del pleno como la confianza del electorado por lo que habría que replantearse la existencia de mecanismos de control basados en la intervención del pleno tal y como ocurre con la moción de censura, que puede dar lugar a la elección de alcaldes alejados de la voluntad popular.

En su origen la moción de censura tiene por objeto garantizar la continuidad de los gobiernos locales en aquellos casos en los que se planteen crisis de gobierno. Pero como en el sistema de elección directa la legitimidad no proviene del pleno sino del electorado, entonces resultaría raro que fuese este órgano quien destituyera a un alcalde mediante la moción de censura retirándole una confianza que nunca le ha otorgado. Tampoco sería coherente si se tiene en cuenta que éxito de una moción de censura y la propuesta de un candidato alternativo, dependen de pactos y alianzas entre los partidos, voluntad política, que puede estar muy alejada de los deseos expresados por el electorado, que es quien otorga la confianza al alcalde(García Morales, 2011:226). 
Los sistemas electorales al nivel municipal no han recibido demasiada atención por parte de los especialistas cuando lo cierto es que ofrecen una gran variedad tanto entre países como en función de los habitantes del municipio. Según un estudio comparativo de la legislación electoral de los principales países de la Unión Europea (en adelante UE) realizado por el Foro Europa Ciudadana, la elección de los alcaldes exige en la mayoría de los países la obtención de una mayoría absoluta para tratar de evitar la celebración de pactos de gobierno poselectorales que debilitaría la legitimidad otorgada por los electores ${ }^{12}$.También se observa como la elección de los alcaldes en segunda vuelta está muy extendida, y se practica con múltiples variantes en otros países europeos. La fórmula cambia, en ocasiones incluso dentro de cada estado, pero en todo caso, intenta responder a las competencias que la ley da a la figura del regidor municipal de cada país ${ }^{13}$.

También existe una gran variedad en el tipo de las listas que se emplean para las elecciones locales. En el caso de Portugal y España, con listas cerradas y bloqueadas, se quiere dar una importancia primordial al partido político. En otros sistemas con listas flexibles, como Austria, Holanda, Suecia, Dinamarca o Finlandia. En algunos sistemas se establece un umbral de votos para ser elegido concejal, como en Suecia, pero en otros como Dinamarca no se establece y simplemente salen elegidos los candidatos en función de su número de votos preferenciales.

Los sistemas que funcionan con un voto preferencial, en el que los ciudadanos tienen la posibilidad de ordenar a los candidatos de más preferidos a menos, equivalen así a una segunda vuelta instantánea. Algunos länder de Alemania o en Noruega se dan tantos votos al elector como cargos ha de elegir y hasta es posible el voto acumulable. En ese sentido, es único -y de complejo recuento- el sistema de voto único transferible de Irlanda (e Irlanda del Norte): el voto de un elector se le asigna inicialmente a su candidato favorito, y si el candidato hubiera sido ya elegido o no supera la cuota de votos, todos los votos sobrantes se transfieren según las preferencias seleccionadas por el elector.

12. http://www.europaciudadana.org/category/legislacion/ (consultada el 10 de septiembre de 2015).

13. Un análisis en profundidad de esta cuestión que abarca un gran amplio número de casos en Municipios de Occidente: El Gobierno Local en Europa y en las América (AAW: 2008). 
En Alemania, por ejemplo, no existe una ley única que regule el proceso electoral, ni tampoco hay una ley que impida las alianzas para gobernar en los ayuntamientos. En las ciudades-Estado las elecciones deciden la composición de una cámara, y ésta elige al alcalde. En 12 estados federados, el regidor es elegido por mayoría absoluta y, si ningún candidato obtiene ese resultado en la primera vuelta, los dos más votados tienen que ir al balotaje (segunda vuelta que se realiza entre los dos candidatos más votados cuando nadie ha obtenido la mayoría requerida), donde les bastará la mayoría simple. En otros cuatro estados, los alcaldes son elegidos por los parlamentos locales, una medida que favorece las alianzas políticas para elegir al futuro alcalde. Tienen derecho a voto en las elecciones municipales los alemanes y ciudadanos de la UE que hayan cumplido 18 años. En ocho estados federados se permite votar con 16 años. Las elecciones tienen lugar cada cuatro, cinco o seis años, según cada Estado (Diez, 2004:233-251).

Finalmente, la otra gran familia son los sistemas de "bonus" proporcionalizado o proporcionales "mayoritarios". Estos son los sistemas que se emplean en la mayoría de municipios de Francia, Italia y Grecia. Según este modelo el partido ganador obtiene siempre, como poco, la mayoría absoluta de representantes en el pleno.

En Italia que cuenta con unos 8.000 ayuntamientos, en los municipios con menos de 15.000 habitantes (y de menos de 10.000, en Sicilia), la elección de los alcaldes es directa: en la papeleta salen los nombres de todos los candidatos y el votante pone una cruz sobre el que quiere que administre el pueblo. Quien tiene más votos sale elegido. Cada candidato puede ser sostenido por una o más listas, que no siempre coinciden con los partidos nacionales. Los símbolos de las formaciones que sostienen a cada candidato alcalde están impresos en la papeleta al lado del nombre correspondiente. El elector puede también marcar el logo de la lista o partido que quiere votar. De esta forma, el voto, además que para el alcalde, sirve también para definir la composición de las futuras junta y asamblea municipal. El elector puede escribir hasta dos nombres de las personas que quiere como concejales. El alcalde ganador tiene derecho a que su equipo ocupe el $60 \%$ de los escaños de la asamblea. El 40\% restante queda en manos de la oposición. En los dos bloques, los puestos se dividen entre los partidos de forma proporcional: la lista con más votos tendrá a más concejales, la con menos, tendrá menos. Las elecciones se llevan a cabo más o menos de la misma forma en los ayuntamientos con más de 15.000 habitantes. La diferencia con los ayuntamientos con menos de 15.000 habitantes, es que en los municipios con población superior, si ningún candidato alcanza la mitad de los votos más uno, se celebra una segunda votación entre los dos candidatos más vo- 
tados. Entonces sí, en las dos semanas que transcurren entre las dos rondas electorales, se consuman acuerdos y alianzas: los partidos o listas que ven "eliminado"' a su candidato, suelen expresarse a favor de uno de los dos contrincantes que quedan. Pero en la urna, cada elector vuelve a decidir.

El sistema electoral en el Reino Unido, tanto en lo que concierne a las municipales como a las legislativas, es nítidamente mayoritario: "el primero que llega, gana", esto es, se impone el candidato más votado con independencia de que tenga o no mayoría absoluta.

La valoración del sistema de elección directa de los alcaldes en países como Italia, Alemania e Inglaterra resulta de gran utilidad para el aprendizaje institucional en otros lugares que como España se han planteado una eventual reforma en esa dirección. En el caso italiano las reformas funcionaron en tres aspectos. Los municipios ganaron en estabilidad de sus gobiernos gracias a la fórmula de la prima de mayoría que mantiene unidos a los plenos y a los alcaldes durante la duración del mandato. Ganan en eficacia al estar en mejor posición para dar respuestas a las demandas ciudadanas y rendirles cuentas de su gestión. Pero quizás el efecto más importante haya sido que con el sistema de elección directa del alcalde se ha conseguido situar a este en una posición central en la gobernanza del municipio desplazando a los partidos y reforzando el liderazgo del alcalde en la medida en la que los votantes son conscientes de quién está al cargo del ayuntamiento. En tercer lugar se ha fomentado la interacción y el diálogo entre alcaldes y representados. Los alcaldes son el centro de las decisiones y lo han aprovechado para desarrollar sus propias políticas y darse a conocer entre su ciudadanía lo que ha contribuido a revalorizar su figura ${ }^{14}$.

En el caso de Alemania el balance que hacen los expertos (Wollmann, 2014: 331-337), es que la capacidad de liderazgo de los alcaldes ha mejorado de manera significativa. Entre los candidatos a las alcaldías se ha fomentado un perfil de candidato profesional por encima del de hombre de partido. La rendición de cuentas entre el alcalde y los ciudadanos es satisfactoria y los alcaldes suelen estar interesados en repetir mandato. Pero a diferencia de lo que ha ocurrido en otros sistemas la participación electoral lejos de aumentar ha disminuido en relación la vigencia del sistema anterior.

En el caso inglés, la diversidad del diseño fue la norma y puede explicar

14. Muchos alcaldes de las ciudades más importantes de Italia revalidaron su cargo en las siguientes elecciones y el propio primer ministro italiano Matteo Renzi llego en 2013 al cargo de Presidente de la República italiana después de su paso por la alcaldia de Florencia. 
su escasa incidencia en la práctica. La Ley ofrecía tres posibilidades para la renovación de los ejecutivos locales: 1) mayor-cabinet: alcalde elegido directamente por todo el electorado y junta de gobierno elegida directamente por él; 2) Leader cabinet: líder elegido por el pleno de entre sus concejales y junta de gobierno nombrada o no por él; 3) Mayor council manager: alcalde elegido directamente por el electorado y gerente nombrado por el pleno ${ }^{15}$. En los primeros años de funcionamiento solo 35 autoridades locales (un 10 por 100) decidieron apostar por la elección directa del alcalde celebrando un referéndum de consulta a sus ciudadanos tal como exigía la ley. El resultado fue que tan solo en 15 casos esta posibilidad de hizo efectiva. La posibilidad de elegir a un líder visible no ha conllevado un aumento de la participación electoral. La participación en este tipo de elección sigue siendo muy baja. El balance en la gestión por parte de los alcaldes elegidos directamente es positivo y ha repercutido en una mejor coordinación entre los diferentes departamentos y administraciones. Las mayores dificultades se observan en aquellos casos donde el alcalde se tiene que enfrentar a un pleno hostil y se ve obligado a trabajar con una junta de gobierno que no le es afín. La reforma también ha tenido un impacto importante sobre los partidos políticos porque con ella ha emergido de manera importante el fenómeno de los independientes en un país donde hasta entonces el 90 por 100 de los concejales pertenecía a uno de los tres grandes partidos nacionales de manera que como se ha señalado de manera muy acertada la elección directa del alcalde ha terminado con "la zona de confort de los partidos en la política local” (Hambleton y Sweeting, 2014: 215-322). El balance de la puesta en práctica del sistema de elección del alcalde en el Reino Unido es incierto y los expertos no acaban de ponerse de acuerdo si ha fracasado o si es una buena respuesta a los problemas que afectan al gobierno local. Lo que sí parecen tenerlo más claro son los líderes nacionales mantienen la apuesta por este sistema de elección como medida para fomentar la democracia local.

15. Estas normas no se aplicaban ni en Escocia ni en Irlanda del Norte. Por su parte Londres ya poseía un sistema de alcalde elegido directamente con un régimen particular que le aporta una notable visibilidad a la alcaldia, lo que hace todavía más complicado el sistema. 


\section{CON CLUSIONES: LACONVEN I E N C I A}

DEL SISTEMA DE ELECCIÓN DIRECTA D E L ACALDE EN ESPAÑA SUS IMPLICACIONES PARA EL GOBIER NO LOCAL

En los países europeos analizados el refuerzo de los ejecutivos locales se ha tratado de implementar a través del sistema de elección directa de sus alcaldes. En España también se ha seguido esta tendencia de fortalecimiento, si bien, por el momento, sin reformar el sistema de elección de los dirigentes municipales. Por eso, llama la atención, que en los estudios comparados sobre esta materia España aparezca incluida dentro del grupo de países con alcaldes fuertes y con amplio elenco competencial sin haber optado por el sistema de elección directa del alcalde por los ciudadanos (Arenilla, 2015: 19-61).

Si se repasan los aspectos que se han ido destacando en el estudio comparado como propios de un alcalde fuerte, no podemos negar que los alcaldes en España tienen una visibilidad y un liderazgo político notable dentro de sus ciudades. Dentro de la estructura municipal, a las competencias legales atribuidas al alcalde, se suman también el apoyo que el alcalde recibe de su propio grupo político en el pleno y una marcada cultura de liderazgo individual que se materializa en su capacidad para nombrar a sus tenientes de alcalde, a los miembros de la junta de gobierno y en general al resto de cargos políticos dentro de la estructura municipal. Por lo que respecta a las elecciones municipales en España, éstas se presentan como disputas electorales entre los diferentes candidatos a la alcaldía y no como confrontaciones entre las listas de concejales y por el mismo motivo, las campañas electorales municipales están fuertemente personalizadas y se centran en aquellos candidatos que encabezan su respectiva lista. Por eso aunque formalmente la elección final del alcalde, está en manos de los concejales, el hecho de que solamente, tal como dispone la ley, los cabeza de lista puedan ser elegidos como alcaldes, otorga a los electores una influencia decisiva a la hora de optar entre las diferentes opciones, por aquella sobre la cual quieren depositar su voto, sin menospreciar sin embargo el papel decisivo de los partidos políticos en la elaboración de dichas listas. La legitimidad electoral también es la adecuada porque si bien la tasa de participación en las elecciones locales está por debajo de la de las elecciones autonómica o estatales, sigue siendo alta en términos comparados con otros países.

En el ámbito institucional, tal y como ya se ha expuesto, el pleno es el otro ámbito donde el alcalde rinde cuentas y donde se escenifica la dinámica gobierno-oposición. La inclusión de mecanismos extraordinarios de control, como la prerrogativa de presentar por parte del pleno una moción de cen- 
sura contra el alcalde, supondría algunos problemas teórico prácticos con los rasgos presidencialistas que se derivan del modelo de elección directa que ya han sido puestos de manifiesto en otros estudios y que tendrían que ser tenidos en cuenta en un hipotético cambio del modelo (Garcia Morales, 2011:241), si bien, lo cierto es que tanto por la dificultad de su puesta en práctica, como por las mayorías exigidas es un mecanismo que se utiliza en pocas ocasiones $^{16}$.

A tenor de estas circunstancias, sí el perfil del alcalde español es el de un líder fuerte, visible, que cuenta con mecanismos de control efectivos sobre su gestión y el sistema electoral ha permitido gobiernos locales estables, y de gran duración en los mandatos de sus alcaldes, habría que preguntarse sobre la oportunidad y conveniencia de emprender un cambio en este sentido en España y sobre todo tratar de aclarar de que hablamos cuando hablamos de elección directa en el sistema español.

La evidencia empírica de los estudios sobre este tema nos permiten concluir que la reforma de las reglas electorales vigentes y en particular sobre la elección directa del alcalde no son realmente una prioridad, sino más bien un reclamos político, puesto que con el sistema electoral vigente se alcanzan los tres objetivos básicos de un sistema democrático: representación, gobernabilidad y legitimidad. Además, y no por obvio hay que dejar de mencionarlo, la neutralidad electoral es casi imposible puesto que cualquier reforma se traduce en algún efecto sobre el sistema político y beneficiará a unos en perjuicio de otros. Eso lleva a que los partidos políticos desarrollen una actitud conservadora cuando se propone la alteración de las reglas del juego, por más que éstas persigan la consecución de unas elecciones más libres, abiertas y competitivas. También explicaría porque no se acomete la reforma del sistema electoral por mucho que cada cierto tiempo, sobre todo ante la inmediatez de elecciones municipales, se plantee tal debate.

Se puede por tanto afirmar que en un sistema de "elección directa del alcal$\mathrm{de}^{\prime \prime}$, son los ciudadanos quienes eligen directamente a quién quieren que sea su alcalde (así ocurre en los länder alemanes o en algunas ciudades inglesas). En casos como el italiano, esa elección directa va vinculada, en mayor o menor medida, a la elección de los concejales integrantes del pleno o de la asamblea municipal. Esta forma de proceder puede ocasionar diná-

16. Según los datos existentes hasta abril de 2014, un año antes de la celebración de las últimas elecciones municipales en España, el número de alcaldes que ha cambiado como consecuencia de una moción de censura o de un cambio de lista has dio de 108 sobre un total de 8.122 municipios (López Nieto 2015:98-99). 
micas conforme a las cuales en las ciudades medianas los partidos políticos no seleccionen sino que más bien apoyen a un candidato "directo" con reputación en su comunidad vecinal otorgándole así al alcalde electo una autonomía política mucho mayor de la que normalmente ofrecen los partidos políticos en otros tipos de elección. Quien es elegido directamente depende directamente de su electorado y sólo secundariamente del partido que le apoya, en caso de que este respaldado por unas siglas concretas. Este sistema rompe el monopolio de los grandes partidos políticos que concurren a las diferentes contiendas electorales en el ámbito estatal, autonómico y local y también contribuye a desvincular de manera más certera la política local de la nacional lo cual podría ser interesante para un sistema municipal como el español con más de ocho mil municipios.

En este sentido la elección directa del alcalde no parece que pueda llevarnos a un cambio drástico en cuanto a la importancia de los partidos y la dependencia de los alcaldes con respecto a los mismos, pero quizás sí en cuanto a la lógica en la selección de los candidatos que respalden sus respectivas siglas. La idea sería crear dinámicas que fomenten una mayor competencia entre los aspirantes para paliar la imposición de los líderes locales desde la dirección de los partidos, abriéndose así un margen de mejora en cuanto a la selección de candidatos y en cuanto a la autonomía de los mismos a la hora de diseñar sus programas de gobierno en clave más local. En estos aspectos la elección directa del alcalde aportaría una revitalización de la política local, pero lógicamente se trataría de un cambio que no solamente debería afectar a la Ley Orgánica del Régimen Electoral General, sino que debería de acompañarse de una reforma en profundidad de la legislación española sobre el régimen local (la vigente Ley 7/1985 Reguladora de las bases del Régimen Local). Es decir, que la elección directa del alcalde exigiría una nueva distribución de poder en el seno del ayuntamiento otorgando más competencias decisorias para el alcalde y su junta de gobierno con el objeto de evitar un enfrentamiento de legitimidades democráticas entre el pleno y el alcalde.

Pero puede ser que el debate abierto en España con motivo de la celebración de elecciones municipales no se sustancie en realidad sobre la elección directa del alcalde. Puede ser que gire más bien sobre la conveniencia para los grandes partidos de ámbito nacional, de que quién finalmente alcance la alcaldía sea el primer candidato de la lista más votada. Esta opción, aunque también legítima, no aporta ninguna de las ventajas que antes se han señalado. De un lado, bajo este supuesto, la elección del alcalde no dependerá de las preferencias ciudadanas sino que se basa en un sistema que fortalece aún más la dependencia entre el candidato a alcalde y el partido 
al que se vincula que es el encargado también de elaborar las listas. Adicionalmente, conllevaría una merma importante del poder de los concejales. Si en el sistema actual son los concejales electos quienes eligen al alcalde, en un sistema de elección automática como el propuesto, el partido ya ha seleccionado y decidido que el alcalde será el primero de la lista si consigue ser la lista más votada. El poder de los concejales para seleccionar entre ellos al candidato más idóneo, queda relegado a un segundo plano porque conforme a este sistema corresponderá al partido seleccionar al candidato que deba encabezar esa lista.

Por otro lado, la elección automática del alcalde de la lista más votada también necesitaría de una redistribución del poder entre los órganos municipales. Porque siendo el alcalde el candidato de una lista minoritaria (aunque relativamente más votada que las demás) se podría producir un conflicto permanente entre el alcalde (con respaldo minoritario en el pleno) y el propio pleno de concejales. Este problema se podría evitar, reforzando el poder decisorio del alcalde y de la junta de gobierno frente al pleno, pero con un impacto nada gratificante para el sistema democrático puesto que se estaría dando el poder de decisión sobre los asuntos municipales a un alcalde que no cuenta con el apoyo mayoritario del electorado y con una representación proporcional en el pleno.

En definitiva la elección directa del alcalde o la elección automática del mismo a través de la lista más votada son dos caras contrapuestas con efectos antagónicos. Con la primera se aumenta el poder de los ciudadanos y la legitimidad democrática del alcalde y mejora su posición frente a las minorías políticas. Con la segunda opción se aumenta el poder de los partidos en su papel de formación de la voluntad política popular y se fortalece el peso del pleno. Si la apuesta es la regeneración democrática evidentemente tendríamos que apostar por la primera porque el elector conocería desde el momento en el que se anuncien los resultados quién va a gobernar el municipio con independencia de la composición del pleno. Esta fórmula podría suponer un aliciente para la participación ciudadana, reducir el abstencionismo y limar las críticas y el malestar de los ciudadanos hacia los partidos políticos.

Pero aun así y teniendo en cuenta que el porcentajes de ayuntamientos con inestabilidad política y dificultades de gobernabilidad es relativamente bajo en el cómputo global y, una vez demostrado que la elección directa del alcalde no soluciona por sí misma los problemas de gobernabilidad porque no garantiza la existencia de mayorías claras en los plenos, quizás la mejor apuesta sea la cautela. 
Sin descartar una futura reforma en este sentido, nuestra propuesta sería analizar de forma más rigurosa otros elementos del sistema electoral que también resultan decisivos a la hora de garantizar una mejor gobernabilidad en el ámbito local ${ }^{17}$ : tipo de mayoría (absoluta o simple); número de vueltas y condiciones para concurrir a la segunda vuelta; la vinculación entre el candidato y el partido (candidatos de partido o independientes); coincidencia de las elecciones a pleno en función de los criterios anteriores; sistema de voto (único o preferencial).

Señalar por último que el debate sobre la reforma electoral local no debería abordarse, tal y como ha ocurrido en España, ante la proximidad de la celebración de elecciones locales. Lo que ha sido posible en otros países como Alemania, Inglaterra, Italia, Portugal o Francia, no es imposible en España y por tanto no hay que descartar la reforma del sistema electoral para dar paso a una elección directa del alcalde. Ahora bien, cualquier propuesta de modificación del sistema electoral debería de presentarse con planteamientos claros, tratando de blindar el debate, en la medida de lo posible, de la presión de los partidos políticos más movidos por su miedo a perder cuotas de poder que por conseguir un mayor fortalecimiento del sistema democrático y tratando de buscar consenso lo más amplio posible que se extienda además a la reforma de otros ámbitos diferentes de la forma de elección del alcalde (normas sustantivas contenidas en la legislación sobre el régimen local) que también son necesarias para dotar a la reforma de la coherencia que precisa. 
AA.VV (2008). Municipios de Occidente: El Gobierno Local en Europa y en las Américas, Giorgia Pavani y Lucio Pegoraro (dirs). Universidad Libre de Bogotá, Bogotá.

Arenilla Sáez, M. (2015). “Sistemas electorales y elección directa del Alcalde. Una perspectiva comparada". En Manuel Arenilla (coord.). La elección directa del alcalde. Reflexiones, efectos y alternativas (p.p. 19-61). Fundación Democracia y Gobierno Local, Madrid.

Calonge Velázquez, A. y González del Teso, T. (1997). El Alcalde. Elección y destitución. Universidad de Valladolid, Valladolid.

Cosculluela Montaner, L. y S. Muñoz Machado (1979). Las elecciones locales. Comentario a la Ley 39/78, de 17 de julio. Abella, Madrid.

De la Torre Martínez, L. (2014). El Estatuto jurídico de los Concejales no adscritos. Fundación Democracia y Gobierno Local, Madrid.

Denter, B. y R. Laurence. (2005): Comparing local governance-trends and developments. Palgrave MacMillan, London.

Diez Sastre, S. (2004). "La elección directa del alcalde en Alemania". En Anuario del Gobierno Local 2004. (pp. 233-251). Fundación Democracia y Gobierno Local-Institut de Dret Públic, Madrid.

Garcia Fernández, J. (2001). “La elección directa de los alcaldes: contexto político y problemática jurídica”. En Revista de Derecho Político, N 52, (pp. 205-245).

García Morales, M. J. (2011). “La elección directa del alcalde en el régimen local. Justificación alcance y repercusiones". En Revista Española de Derecho Constitucional, ${ }^{\circ}$ 91, enero-abril, (pp. 205-258).

Gavara de Cara, J.C. (2015). "La elección directa del alcalde en la forma de gobierno local". En Manuel Arenilla (coord.). La Elección directa del Alcalde. Reflexiones, efectos y alternativas (pp.161-186). Fundación Democracia y Gobierno Local, Madrid.

Hambleton, R. y D. Sweeting. (2014). “Innovation in urban political leadership. Reflections on the introduction of a directly-elected mayor in Bristol, UK". En Public Money and Management, 34(5), pp. 215-322.

López Nieto, L (2015). “'Modificar el sistema de elección del alcalde?”. En Manuel Arenilla (coord.). La elección directa del alcalde. Reflexiones, efectos y alternativas (pp. 63-104). Fundación Democracia y Gobierno Local, Madrid.

Mahíllo P. y Galán, A. (2015). “La reforma del régimen electoral: el alcalde entre la elección directa y la designación automática”. En Manuel Arenilla (coord.). La elección directa del Alcalde. Reflexiones, efectos y alternativas, (pp. 187-209). Fundación Democracia y Gobierno, Madrid. 
Márquez Cruz, G. (2007), Política y gobierno local. La formación de gobierno en las Entidades locales en España. Madrid. Centro de Estudios Políticos y Constitucionales.

Ministerio de Administraciones Públicas (2005). Libro Blanco para la Reforma del Gobierno Local. Secretaría General Técnica, Madrid. Disponible en http://www.seap.minhap. gob.es/dms/es/web/publicaciones/centro_de_publicaciones_de_la_sgt/Monografias/ parrafo/0111111111111111118/text_es_files/Libro-Blanco-Gobierno-Local.pdf

Montero, J.R. y otros (2015). “Elecciones municipales en España (1979-2011): las dimensiones del voto". En Manuel Arenilla (coord.). La elección directa del alcalde. Reflexiones, efectos y alternativas (pp. 105-139). Fundación Democracia y Gobierno Local, Madrid.

Navarro, C. y D. Sweeting. (2015). "La elección directa de alcaldes. Características, experiencias comparadas y el singular caso de los alcaldes quasi-directamente elegidos españoles". En Anuario de Derecho Municipal. (pp. 105-216). Marcial Pons-Universidad Autónoma de Madrid, Madrid.

Pendás, B. (1993). "El sistema electoral en las elecciones locales", IV Jornadas de Derecho Parlamentario. Reflexiones sobre el régimen electoral. (pp. 573-574). Congreso de los Diputados, Madrid.

Salazar Benítez, O. (2003). "La elección directa del Alcalde". En Revista Almirez, (12), (pp. 51-78).

Salazar Benítez, O. (2006). "Las elecciones locales y sus efectos en el sistema de gobierno municipal", en Revista Administración \& Cidadanía. Escola Galega de Administración Pública, Vol. 1, N², pp. 151-173.

Salazar Benítez, O. (2007). El sistema de Gobierno municipal. Centro de Estudios Políticos y Constitucionales, Madrid.

Salvador Crespo, M. (2008). “El equilibrio de poderes en el ámbito municipal en España". En Mayte Salvador Crespo, Héctor Pérez Pintor, Gerardo Ruiz-Rico Ruiz (Coord). Estudios Municipales. Una Visión desde México y España. (pp. 81-10). Colección: Estudios Jurídicos, Serie: Derecho, Municipal 1. Universidad Michoacana de San Nicolás de Hidalgo, Morelia,

Wollmann, H. (2014). “The directly-elected mayor in the German Länder, introduction, implementation and impact". En Public Money and Management, $\mathrm{N}^{\circ} 34(5)$, (pp. 331-337).

Zafra Víctor, M. (2009). “Código de conducta política en relación con el transfuguismo en los gobiernos locales". En Pablo Santolaya Machetti, Jesús María Corona Ferrero, María Díaz Crego (coords). Transfuguismo político: escenarios y respuestas. (pp. 593-600). Civitas, Madrid. 